\title{
Effect of Coating Amino Acids with Casein Supplemented to Gelatin Diet on Plasma Free Amino Acids of Carp
}

\author{
Takeshi Mural*1, Toshio AkIYama*1, Hiroshi OGata*1 \\ Yasuhiro HIRASAWA ${ }^{* 2}$, and Takeshi NOSE*1
}

(Received October 2, 1981)

\begin{abstract}
Levels of free amino acids were examined in plasma of carp at $0.5,1,1.5,2,3,4,6,8,12$, and 24 hours after being fed casein-gelatin (control), gelatin (diet 2), and gelatin diet with essential amino acids uncoated (diet 3 ) or coated with casein (diet 4). Also, the balance of essential amino acid in plasma (BEAAp) was calculated in a manner similar to that for the determination of EAA index, using those of the control group as references. Almost all EAA in fish fed diets 3 and 4 reached maximal levels and dropped to fasting levels faster than in fish fed the control diet. In fish fed diet 4, levels of tryptophan were higher, but those of leucine were lower throughout the 1-8 hour period, than in fish fed diet 3; levels of all EAA (except lysine and arginine) from fish fed diet 2 remained low, with vague peaks at 4 hours. Values for BEAAp in all treatments dropped to the lowest values at 6 hours after feeding. Those for diets 2,3 , and 4 were $32.3,57.9$, and $86.7 \%$ respectively and those from diet 4 were always higher than those from diet 3 . Highly significant correlations between the BEAAp value at 6 hours and the average weight gain, feed efficiency, or protein efficiency ratio were confirmed. These results indicated that coating amino acids with casein improved plasma amino acid balance, probably by altering the absorption and retention times of tryptophan and leucine.
\end{abstract}

In a previous study, ${ }^{1)}$ we reported that fingerling carp fed a gelatin diet supplemented with essential amino acids (including tyrosine) coated with casein showed a comparable growth to fish fed a casein-gelatin diet. These fish achieved more than four-fold faster growth and almost twofold better feed efficiency than fish fed a gelatin diet with the same amino acids but uncoated. It is reported in man that the rates at which individual amino acid is absorbed from an amino acid mixture are unequal to those absorbed through normal digestion process of intact proteins." Because simultaneous presentation of amino acids to the tissues is necessary for optimal protein synthesis, ${ }^{3)}$ we proposed a hypothesis that coating amino acids with casein minimized variation in absorption rate of individual amino acid. ${ }^{1)}$

Since plasma levels of free essential amino acids are shown to be positively correlated to those in a diet, ${ }^{4,8)}$ changes in plasma levels of free amino acids of carp at various time intervals after being fed casein-gelatin, gelatin, and gelatin diets with supplemental crystalline amino acids either coated or uncoated with casein were determined to test the hypothesis described above. To carry out this object more precisely, values for balance of essential amino acids in the plasma at various time intervals were calculated in a manner similar to that for the determination of essential amino acid index (EAA index).

\section{Materials and Methods}

Experimental diets used were exactly the same as previously used ${ }^{1 /}$ and $\mathrm{A} / \mathrm{E}$ ratios (each essential amino acid including cystine and tyrosine/total essential amino acids $\times 100$ ) for each diet are shown in Table 1. Carp fingerlings (mean weight of approximately $35 \mathrm{~g}$ ) stocked separately in five polyvinyl chloride tanks $(55 \times 30 \times 35 \mathrm{~cm})$ with 70 fish per tank had been fed the casein-gelatin diet (control diet) for 2 weeks. The remaining experimental conditions were similar to those reported previously. ${ }^{1)}$ Fish were starved for 24 hours and then blood samples for zero time were taken from 6 fish (two pooled samples) in one of the tank. Then fish in the rest of tanks were fed the following diets one by one ( 20 minutes apart) as much as

*1 Division of Fish Nutrition, National Research Institute of Aquaculture, Hiruta, Tamaki, Watarai, Mie

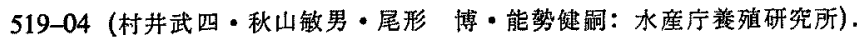

*2 Faculty of Fisheries, Mie University, Edobashi, Tsu, Mie 519 (平沢康弘: 三重大学水险学部). 
Table 1. A/E ratios ${ }^{* 1}$ of the experimental diets ${ }^{1}$

\begin{tabular}{|c|c|c|c|c|c|c|c|c|c|c|c|c|}
\hline & Diet No. & Treatment & Arg & His & Ile & Leu & Lys & $\begin{array}{c}\text { Met } \\
+ \\
\text { Cys }\end{array}$ & $\begin{array}{c}\text { Phe } \\
+ \\
\text { Tyr }\end{array}$ & Thr & Trp & Val \\
\hline & 1 & $\mathrm{Cas}+\mathrm{Gel}(\text { control })^{* 2}$ & 10.0 & 5.1 & 8.4 & 16.6 & 14.1 & 6.4 & 18.3 & 8.7 & 1.7 & 10.7 \\
\hline & 2 & $\mathrm{Gel}^{* a}$ & 31.1 & 6.9 & 6.1 & 12.4 & 16.7 & 3.4 & 9.3 & 4.4 & - & 4.7 \\
\hline & 3 & $\mathrm{Gel}+\mathrm{AAs}^{* 4}$ & 10.1 & 5.1 & 8.4 & 16.6 & 14.2 & 6.4 & 18.3 & 8.7 & 1.7 & 10.6 \\
\hline & 4 & Gel+Coated AAs*s & 10.1 & 5.1 & 8.4 & 16.6 & 14.1 & 6.4 & 18.4 & 8.7 & 1.7 & 10.6 \\
\hline & \multicolumn{12}{|c|}{ Each essential amino acid/total essential amino acids including cystine and tyrosine $\times 100$. } \\
\hline *2 & \multicolumn{12}{|c|}{ Casein $(25 \%)+$ Gelatin $(10 \%)$} \\
\hline$* 3$ & \multicolumn{12}{|c|}{ Gelatin $(35 \%)$} \\
\hline *4 & \multicolumn{12}{|c|}{ Gelatin $(24 \%)+$ Crystalline amino acids $(\mathrm{His}, 0.52 ; \mathrm{Mle}, 0.91 ;$ Leu, $1.80 ; \mathrm{Lys} . \mathrm{HCl}, 1.55 ;$ Met, $0.76 ;$ Phe, $0.96 ; \mathrm{Tyr}, 1.22 ; \mathrm{Thr}, 0.92$} \\
\hline$* 5$ & \multicolumn{12}{|c|}{ Gelatin $(21 \%)+$ Casein coated amino acids (Arg, $0.11 ; \mathrm{His}, 0.64 ; \mathrm{Hle}, 1.12 ;$ Leu, $2.22 ; \mathrm{Lys} \cdot \mathrm{HCl}, 1.91 ; \mathrm{Met}, 0.99 ; \mathrm{Phe}, 1.20 ; \mathrm{Tyr}, 1.49$} \\
\hline
\end{tabular}

fish could cosume in 7 minutes; control diet (diet 1), gelatin diet (diet 2), gelatin diets supplemented with uncoated amino acids (diet 3 ) and coated amino acids (diet 4). In all treatments, amounts of diets consumed were approximately the same.

About $0.4 \mathrm{~m} l$ of whole blood was withdrawn from the caudal vein-artery complex with a heparinized $1 \mathrm{~m} l$ syringe from six individual fish in each dietary group at $0.5,1,1.5,2,3,4,6,8,12$, and 24 hours after feeding the respective diets. In all cases, three blood samples were pooled to one. Each time fish were netted with a minimum disturbance and anesthetized with a MS-222 (1: 10,000) solution. The pooled blood samples were immediately centrifuged at $2,500 \mathrm{rpm}$ for 10 minutes.

Approximately $0.4 \mathrm{ml}$ of plasma sample was transferred to a centrifuge tube and the protein was precipitated by the addition of equal volume of $10 \%$ sulfosalicylic acid. ${ }^{\text {() }}$ After a 10 minute shaking with a mechanical shaker, the suspention was centrifuged at $10,000 \mathrm{rpm}$ (at $5^{\circ} \mathrm{C}$ ) for 15 minutes. The supernatant fluid was taken and stored at $-70^{\circ} \mathrm{C}$ to prevent loss of glutamine and cystine $^{73}$ untill analyzed. Free amino acids were determined using an automatic amino acid analyzer (Hitachi Model 835).

Values for balance of essential amino acids in plasma (BEAAp) at each period was calculated by comparison of the plasma $A / E$ ratios in the test groups with those in the control groups as follows:

$$
\sqrt[10]{\frac{100 \mathrm{a}}{\mathrm{ac}} \times \frac{100 \mathrm{~b}}{\mathrm{bc}} \times \frac{100 \mathrm{c}}{\mathrm{cc}} \times \cdots \times \frac{100 \mathrm{j}}{\mathrm{jc}}},
$$

where $a, b, c, \ldots j$; plasma $A / E$ ratio for each essential amino acid when test diet was fed, and $a c, b c, c c, \ldots j c$; plasma $A / E$ ratio for each essential amino acid when the control diet was fed.

\section{Results}

\section{Plasma Levels of Free Amino Acids}

Essential amino acids including tyrosine were classified based on the polarity of $\mathrm{R}$ groups (side chains) at $\mathrm{pH} 6-7,{ }^{8}$ (1) nonpolar or hydrophobic (Val, Leu, Ile, Phe, Trp, Met), (2) polar but uncharged (Thr, Tyr), (3) positively charged (Lys, Arg, His). In all figures, each point represents the mean value of two pooled samples. Although the composition of the experimental diets except the gelatin diet (diet 2) were almost identical (Table 1), marked differences in levels of free amino acids in plasma were observed among dietary treatments with or without supplemental crystalline amino acids. However, in each amino acid class, patterns of sequential changes in amino acid levels from these dietary treatments were relatively similar. While those from diet 2 showed completely different patterns, and concentrations of lysine and arginine showed marked increase reflecting the dietary levels, but throughout the experimental period the rest of essential amino acids remained low with vague peaks at 4 hours.

1. Amino acids with nonpolar or hydrophobic $\mathrm{R}$ group (Figs. 1, 2).

Plasma levels of valine, leucine, phenylalanine and tryptophan from fish fed the control diet (diet 1) rose relatively quickly reaching maximal values at 3 to 4 hours after feeding, but levels of methionine and isoleucine increased slowly attaining the highest values at 4 hours. Whereas the plasma levels of all these amino acids from both groups of fish fed the diets with amino acids uncoated (diet 3) or coated (diet 4) increased rapidly and attained the peaks in 1 or 2 hours. The peaks of phenylalanine, tryptophan and methionine in these groups were much higher, but their levels became lower than those of the control groups by 3 hours. Only 


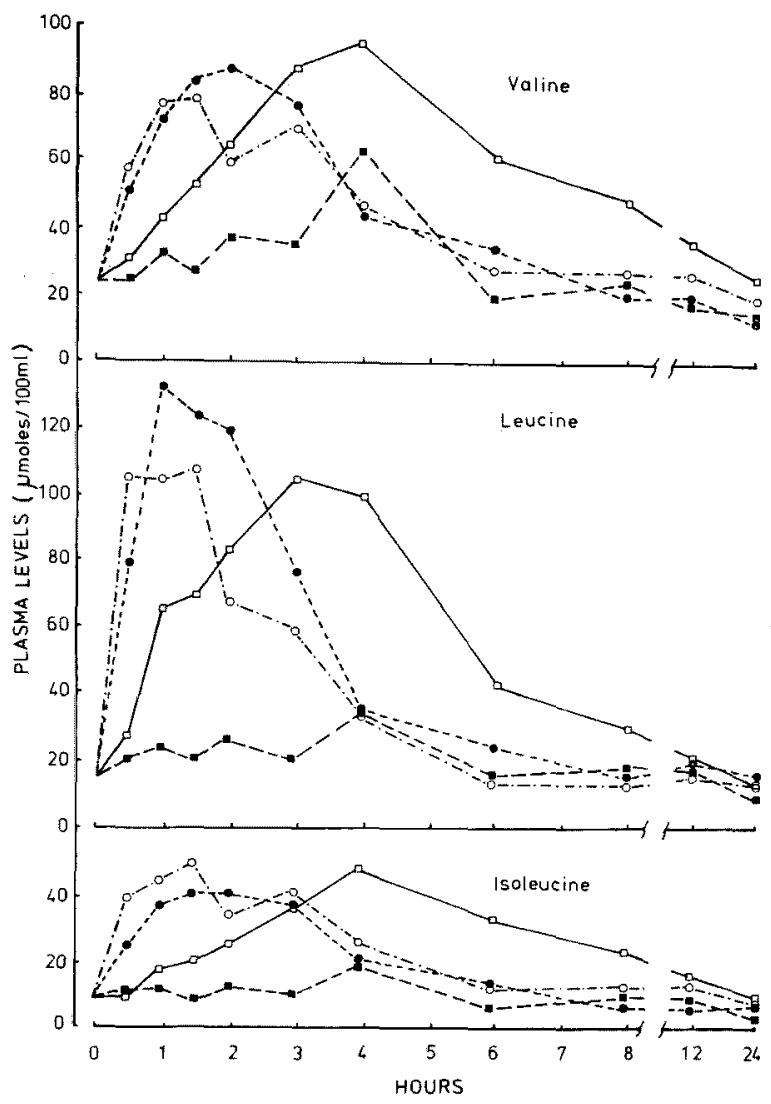

Fig. 1. Change in the level of plasma free valine, leucine, and isoleucine of carp at various time intervals after feeding the following diets; casein-gelatin ( $\square-\square)$, gelatin (1---m), gelatin with uncoated amino acids (---), and gelatin with coated amino acids $(0-\cdot-0)$.

striking differences noted between fish fed diet 3 and 4 were levels of tryptophan and leucine, that is, in the former, tryptophan levels were always lower, while leucine levels remained higher almost all the times than in the latter. Levels of all amino acids in this class from the control group were higher between 4 and 8 hour period except tryptophan levels at 6 and 8 hours than those from groups of diet 3 and 4.

2. Amino acids with polar but uncharged $R$ group (Fig. 3).

Unlike amino acids in the previous class, only slight differences were observed in patterns of changes in plasma levels of threonine and tyrosine between fish fed the control diet and diet 3 or 4 . Concentrations of these amino acids gradually increased and then decreased slowly.

3. Amino acids with positively charged $\mathrm{R}$ group (Fig. 4).
Concentrations of plasma lysine from fish fed diets 3 and 4 reached maximal levels in 1 hour and returned to almost fasting level by 4 hours. While that from diet 1 reached the highest level at 2 hours and dropped to the fasting level at 6 hours. Although almost no crystalline arginine was added to diet 3 or 4 , peak levels of arginine from these diets were higher than that from diet 1 , which were attained in 1 hour. Concentration of plasma histidine from fish fed diet 1 became relatively high in 1 hour and this level was kept for 4 hours, while those from diets 3 and 4 attained peak levels in a similar manner, but dropped to the fasting level by 4 hours. Common phenomenon among amino acids in this class observed in all treatments was slight elevation in concentrations of these amino acids at 12 hours.

4. Total amino acids (Fig. 5).

Sequential changes in total essential amino acids 


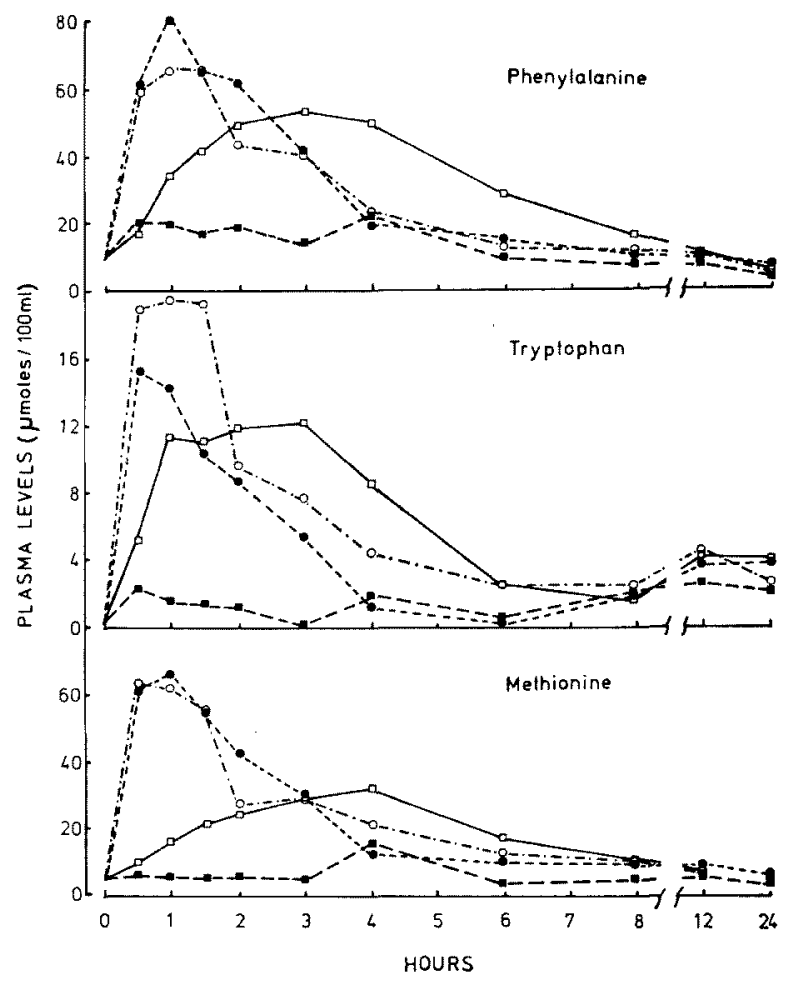

Fig. 2. Change in the level of plasma free phenylalanine, tryptophan, and methionine of carp at various time intervals after feeding the following diets; casein-gelatin ( $\square-\square$ ), gelatin ( $(\mathbf{\square - m})$, gelatin with uncoated amino acids $(\bullet---\bullet)$, and gelatin with coated amino acids $(0-\infty)$.

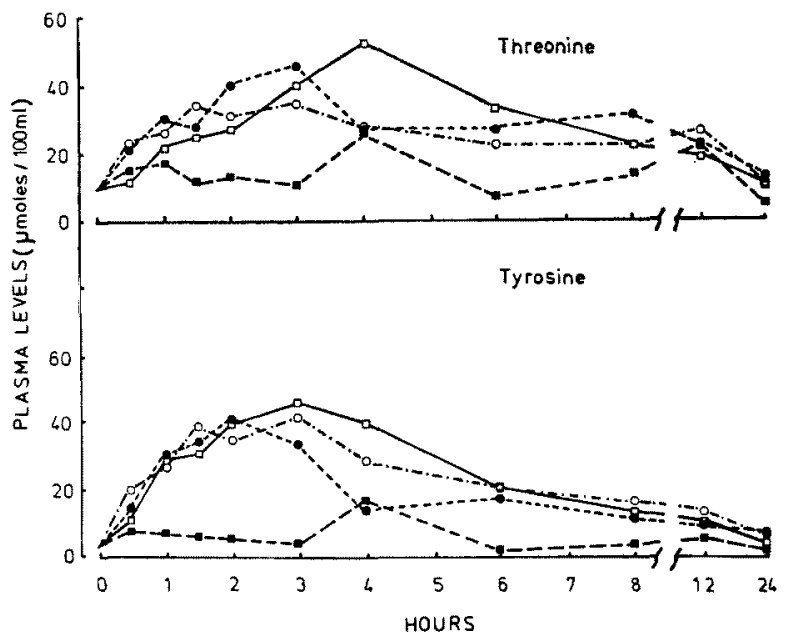

Fig. 3. Change in the level of plasma free threonine and tyrosine of carp at various time intervals after feeding the following diets; casein-gelatin ( $\square-\square)$, gelatin ( $1---\mathbf{D})$, gelatin with uncoated amino acids (---), and gelatin with coated amino acids $\left(\mathrm{O}_{-} \cdot-\mathrm{O}\right)$. 


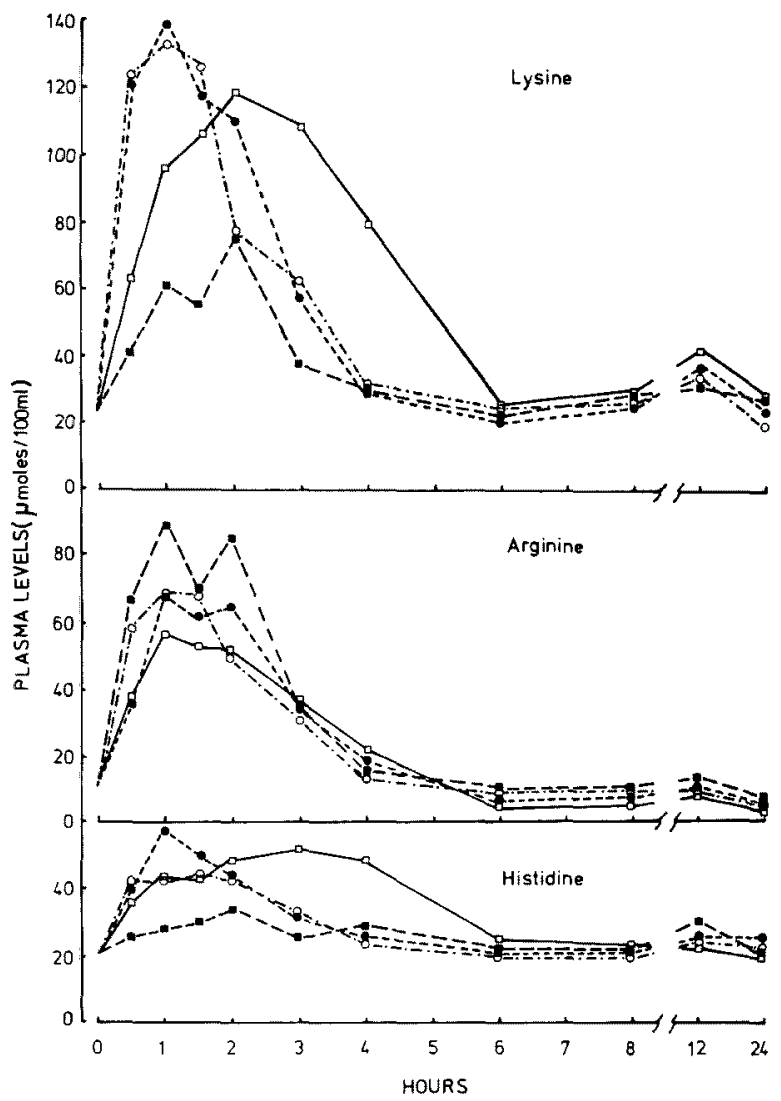

Fig. 4. Change in the level of plasma free lysine, arginine, and histidine of carp at various time intervals after feeding the following diets; casein-gelatin $(\square-\square)$, gelatin ( $\square---\square)$, gelatin with uncoated amino acids (---), and gelatin with coated amino acids $(0-.-0)$.

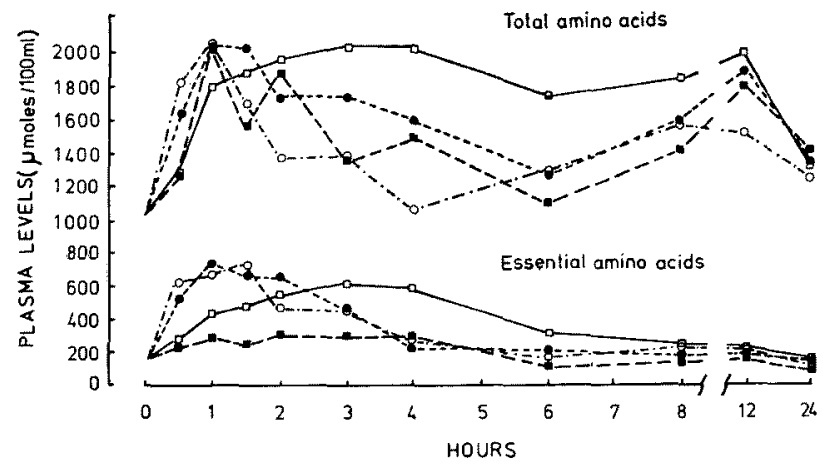

Fig. 5. Change in the level of plasma free total amino acids and essential amino acids of carp after feeding the following diets; casein-gelatin ( $\square-\square$ ), gelatin (1--- - ), gelatin with uncoated amino acids (--O), and gelatin with coated amino acids $(\mathrm{O}-\cdot-\mathrm{O})$. 


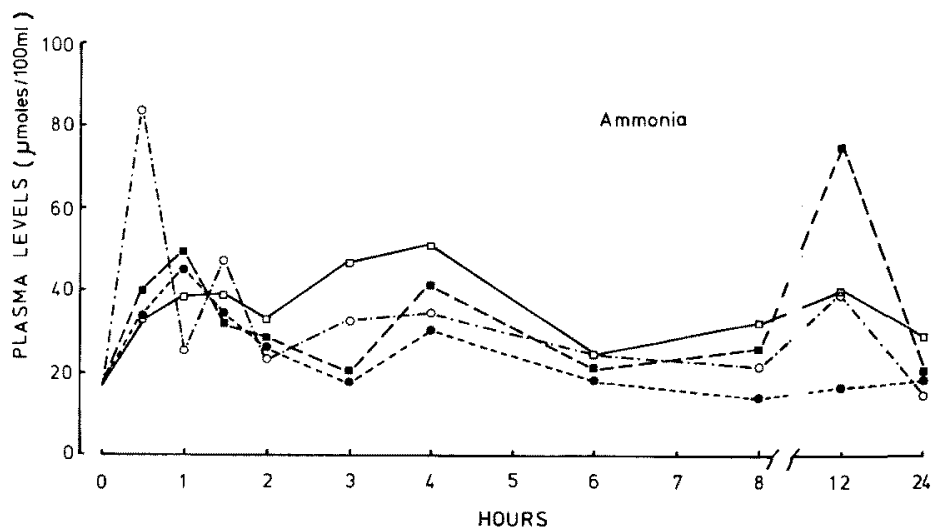

Fig. 6. Change in the level of plasma ammonia of carp after feeding the following diets; caseingelatin ( $\square-\square)$, gelatin ( $\mathbf{(}---\mathbf{m})$, gelatin with uncoated amino acids (----), and gelatin with coated amino acids $(\mathrm{O}-\mathrm{-}-\mathrm{O})$.

Table 2. Balance of essential amino acids in the plasma (BEAAp)*1

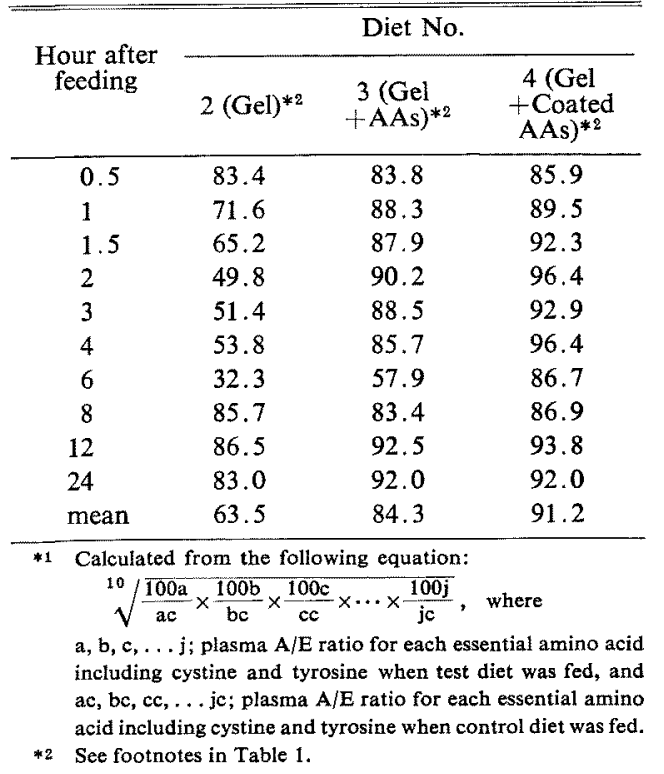

including tyrosine from fish fed diet 3 and 4 were in a similar pattern. The maximal levels of that were attained in 1 to 1.5 hours and dropped to the fasting level by 4 hours. While that for diet 1 gradually increased until at 3 hours and then decreased slowly. After 3 hours the concentrations from diet 1 were always higher than those from the other diets. The levels of that from fish fed diet 2 were slightly higher than the fasting level during only 0.5 to 4 hour periods. Concentrations of cystine in all treatments remained less than 2 $\mu$ moles per $100 \mathrm{~m} l$ of plasma throughout the experimental period. Also, dietary treatments had little effect on taurine levels which were between 40 and $80 \mu$ moles per $100 \mathrm{~m} l$ of plasma. Sequential changes in plasma ammonia levels observed in all treatments (Fig. 6) were generally similar to those of total amino acids.

\section{Balance of Essential Amino Acids in Plasma (BEAAp)}

Data on BEAAp are summarized in Table 2. BEAAp value for diet 2 gradually decreased after

Table 3. Evaluation of the experimental diets

\begin{tabular}{|c|c|c|c|c|c|c|c|}
\hline \multirow{2}{*}{$\begin{array}{l}\text { Diet } \\
\text { No. }\end{array}$} & \multirow{2}{*}{ Treatment*1 } & \multirow{2}{*}{$\underset{\text { gain }^{1\rangle}}{\text { Avg wt }}$} & \multirow{2}{*}{$\begin{array}{c}\text { Feed } \\
\text { efficiency }^{1)}\end{array}$} & \multirow{2}{*}{ PER $^{1)}$} & \multirow{2}{*}{ EAAI $* 2$} & \multicolumn{2}{|c|}{ BEAAp*3 } \\
\hline & & & & & & at $6 \mathrm{hr}$ & mean \\
\hline 1 & $\mathrm{Cas}+\mathrm{Gel}$ (control) & 8.29 & 99.56 & 3.02 & 68.12 & 100 & 100 \\
\hline 2 & Gel & -0.04 & -0.01 & -0.02 & 22.41 & 32.28 & 63.53 \\
\hline 3 & $\mathrm{Gel}+\mathrm{AAs}$ & 1.74 & 30.95 & 0.96 & 69.17 & 57.94 & 84.33 \\
\hline 4 & Gel + Coated AAs & 7.26 & 83.46 & 2.67 & 71.65 & 86.70 & 91.20 \\
\hline
\end{tabular}

*1 See footnote in Table 1 .

*2 Essential amino acid index (whole egg protein as a reference).

* B Balance of essential amino acids in plasma (see footnote in Table 2). 
Table 4. Correlation coefficients

\begin{tabular}{llll}
\hline & $\begin{array}{c}\text { Avg wt } \\
\text { gain }^{12} \\
(\mathrm{~g})\end{array}$ & $\begin{array}{c}\text { Feed } \\
\text { efficiency } \\
(\%)\end{array}$ & PER $^{12}$ \\
\hline EAAI*1 & 0.713 & 0.772 & 0.769 \\
BEAAp (at 6 hr) $^{* 2}$ & $0.981^{*}$ & $0.996^{* *}$ & $0.994^{* *}$ \\
BEAAp (mean) $^{* 2}$ & 0.909 & 0.949 & 0.944 \\
\hline
\end{tabular}

-1 Essential amino acid index.

*2 Balance of essential amino acids in plasma. $* P<0.05, * * P<0.01$

feeding and dropped to the lowest level of $32.3 \%$ at 6 hours. Then it increased to $85.7 \%$ at 8 hours and kept a constant level thereafter. Changes in BEAAp values for diets 3 and 4 were in a similar pattern, i.e. those increased gradually after feeding and decreased to the lowest levels at 6 hours. However, those for diet 4 were always higher than those of diet 3. The lowest value for diet 4 was almost $30 \%$ higher than that of diet 3 .

Data from the previous study, ${ }^{1)}$ EAA index and BEAAp value (mean and at 6 hours) are summarized in Table 3. As shown in Table 4, significant correlations between BEAAp value at 6 hours and average weight gain $(P<0.05)$, feed efficiency $(P<0.01)$, and protein efficiency ratio $(P<0.01)$ were obtained. Whereas, correlations between EAA index or mean BEAAp value and these data were not statistically significant $(P>0.05)$.

\section{Discussion}

In both groups of fish fed the gelatin diets with coated and uncoated amino acids, sequential changes of all essential amino acids were in relatively similar patterns, which were completely different from those of fish fed the casein-gelatin diet as this phenomenon has been recognized in man. ${ }^{2}$ Since times required to attain the highest concentrations of all essential amino acids in plasma from fish fed the diet with coated amino acids were almost half of those in fish fed the control diet, even crystalline amino acids coated with casein seemed to be absorbed as quickly as those uncoated as has been reported by AOE et $a l^{\left.{ }^{\theta}\right)}$ and TANAKA et al. ${ }^{10)}$ Thus drastic improvement in utilization of crystalline amino acids by coating with casein ${ }^{1}$ suggest that quick absorptions and short retention times of amino acids may not be a major reason for poor utilization of crystalline amino acids by carp. Plakas et al. ${ }^{52}$ suggested a possibility of stimulated amino acid catabolism in carp fed an amino acid diet, judging from higher generation rate of ammonia in plasma at 2 hours after feeding this diet. But this phenomenon was not recognized in our study. In their report, ${ }^{5)}$ no significant difference in amino acids absorption rates or retention times was obtained between groups fed the amino acid diet and casein diet. These contradictions may be resulted from differences in diet compositions.

Always better BEAAp values for the group with coated amino acids than those for the group with uncoated amino acids clearly indicated that coating amino acids with casein could improve balance of essential amino acids in the tissues particularly due to alternations of tryptophan and leucine levels. Furthermore, significant correlations between BEAAp at 6 hours and growth, feed efficiency or protein efficiency ratio from the previous study ${ }^{1}$ would strongly support the hypothesis that coating amino acids with casein minimized variations in absorption rate of certain amino acids and resulted in relatively simultaneous presentation of amino acids for optimal protein synthesis.

Since fish were fed the test diets only once, higher levels of total amino acids at 8 and 12 hours in all treatments than those at 6 hours indicated that part of these amino acids were mobilized from metaboric pools in the body which was still intact. This might be a reason for improved BEAAp values after 6 hours even in group fed the gelatin diet and poor fitness of mean BEAAp value. HARKER et al. ${ }^{11)}$ reported that the nutritive quality of protein or amino acid mixture is reflected most accurately in plasma obtained after 6 hours of fasting in their rat study.

These results clearly indicated that balance of essential amino acids may be more important than absorption rate or retention time of individual amino acid for efficient utilization. And by coating essential amino acids with casein, balance of these amino acids in the tissues can be improved. Measurement of BEAAp value at 6 hours might be a rapid and reliable mean of assessing the quality of a diet with supplemental amino acids especially for carp. Whereas EAA index which has been shown to be a good index for indication of dietary protein quality even in fish ${ }^{12)}$ may not be suitable for carp when diet contains crystalline amino acids.

\section{References}

1) T. Murai, T. Akiyama, and T. Nose: Bull. Japan. Soc. Sci. Fish., 47, 523-527 (1981).

2) D.B.A. Silk, T. C. Marrs, J. M. Addison, D. Burston, M. L. Clark, and D. M. Matthews: 
Clin. Sci. Mol. Med., 45, 715-719 (1973).

3) D. M. MATthews: Gastroenterology, 73, $1267-$ 1279 (1977).

4) T. Nose: Bull. Freshwater Fish. Res. Lab., 22, 137-144 (1977).

5) S. M. Plakas, T. Katayama, Y. Tanaka, and $O$. Deshimaru: Aquaculture, 21, 307-322 (1980).

6) W. D. Block, M. E. Markovs, and B. R. STeEle: Proc. Soc. Exp. Biol. Med., 122, 1089-1091 (1966).

7) L. D. SteginK, L. J. FILER, and G. L. BAKER: J. Nutr., 107, 1837-1845 (1977).

8) A. L. LehNiNger: Protein: The amino acid building blocks, in "Biochemistry" (ed. A. L.
LehNINGer), Worth Publishers, Inc, New York, 1970, pp. 67-87.

9) H. Aoe, I. Masuda, I. Abe, T. Saito, T. Toyoda, and S. Krtamura: Bull. Japan. Soc. Sci. Fish., 36, 407-413 (1970).

10) Y. Tanaka, S. Hokazono, T. Katayama, K. L. Simpson, and C. O. Chichester: Mem. Fac. Fish. Kagoshima Univ., 26, 39-43 (1977).

11) C.S. Harker, P.E. Allen, and H. E. Clark: J. Nutr., 94, 495-503 (1968).

12) T. Nose: Bull. Freshwater Fish. Res. Lab., 13, 41-50 (1963). 